صورة الموت في النص الثعري بين فيدريكو غارثيا لوركا و أمل دنقل

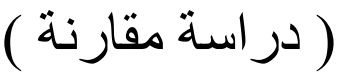

منصور محسن ضباب

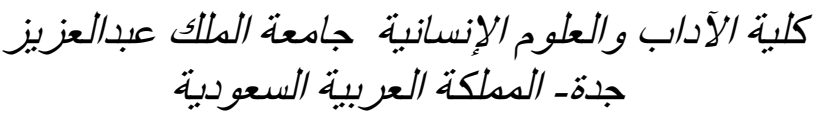

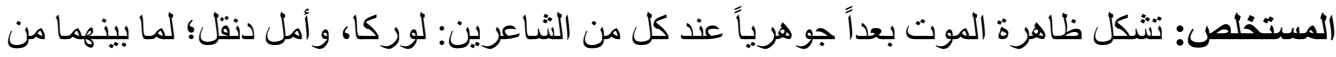

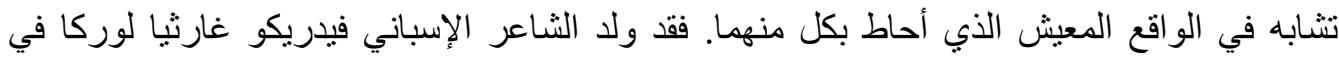

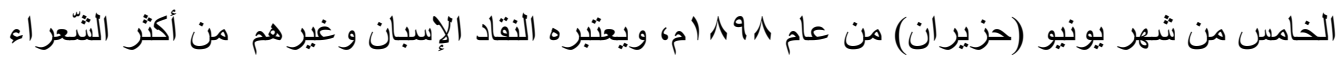

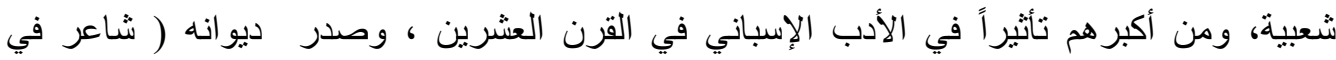

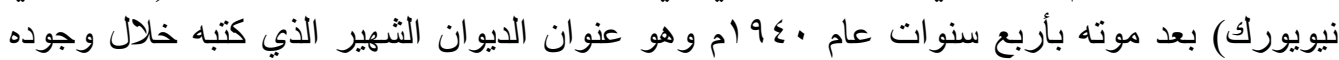

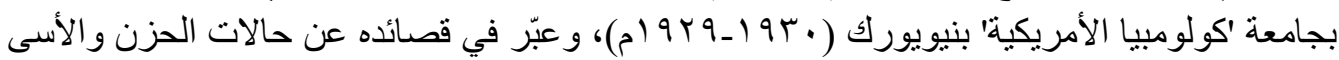

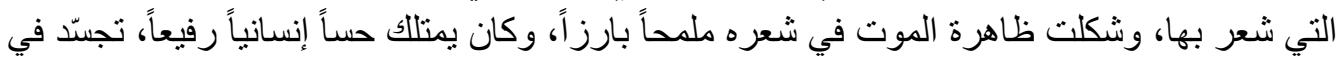

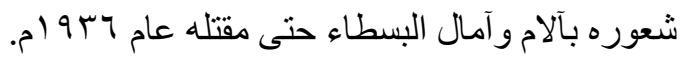

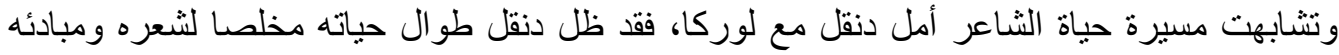

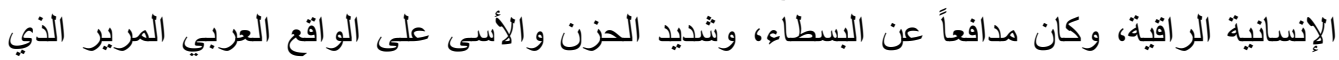

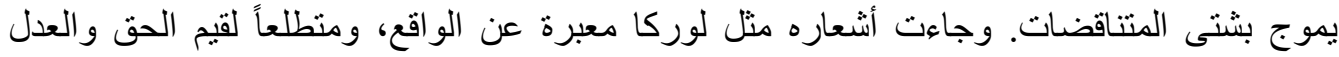
و والحرية.

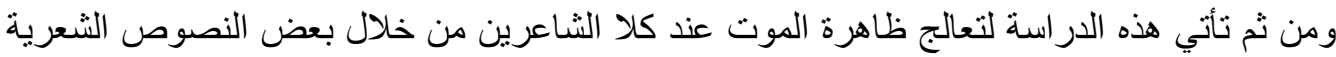

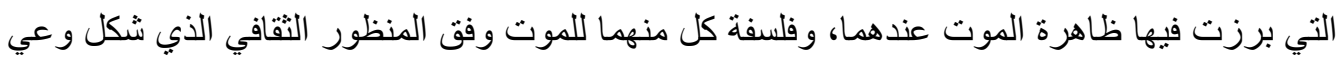

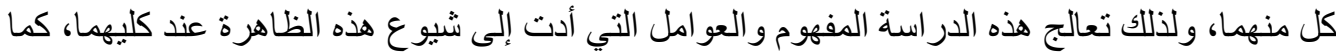

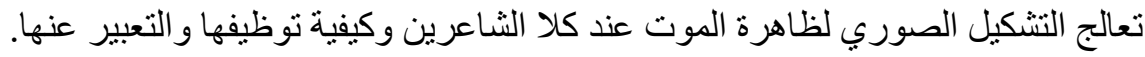
الكلمات المفتاحية: لوركا، أمل دنقل، در اسة مقارنة.

\section{مقدمة}

القرن العشرين بحثاً عن استقلاله خلال القرن

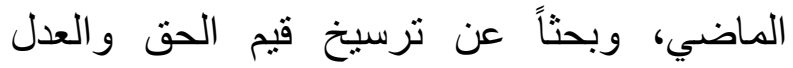

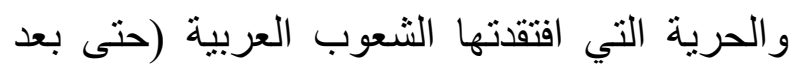
حصولها على الاستقلال).

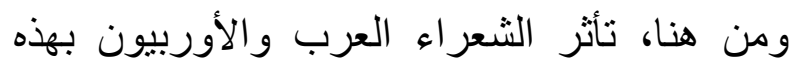
المتغيرات والصر اعات، ولأن هذه الظاهرة شكلت الأوربون بهن

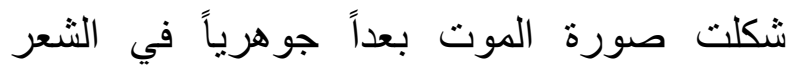

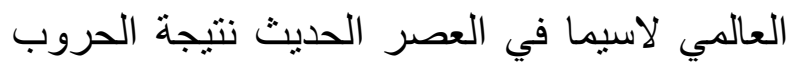
والصراعات الدموية التي مر بها لاعبا المجتمعان:

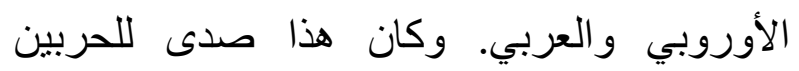

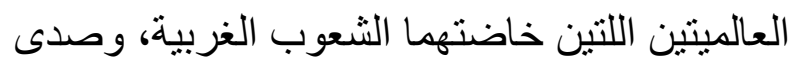
أيضاً للصر اعات التي شهدها المجتمع العربي طو ال 
ومن أكبرهم تأثثراً في الأدب الإسباني في القرن

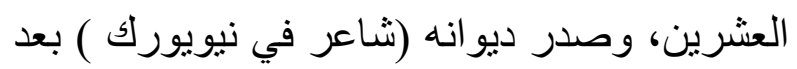

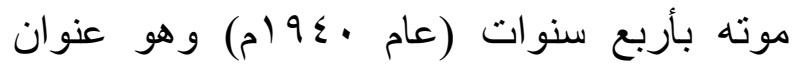

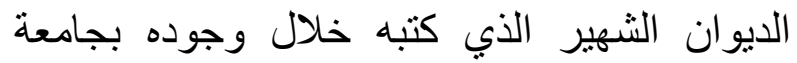

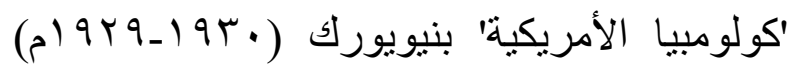

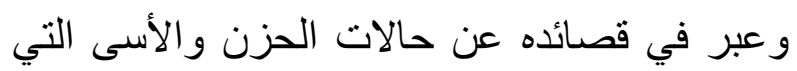
شعر بها، وشكلت ظاهرة الموت في شعره ملمحا

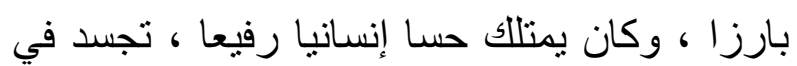
شعوره بآلام وآمال البسطاء حتى يلى مقتله عام (9 وتثابهت المسيرة الحياتية لكلا الثشاعرين فكل منهما

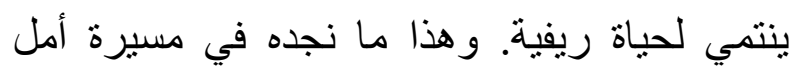

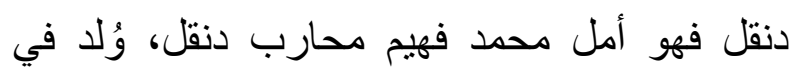

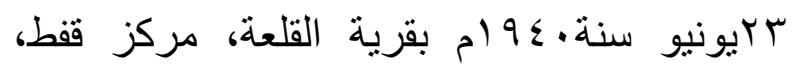

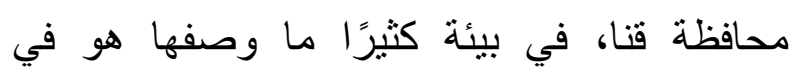

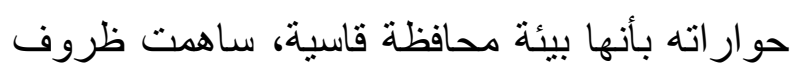

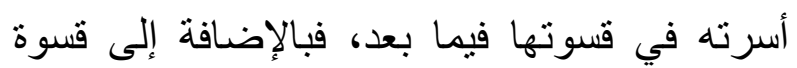

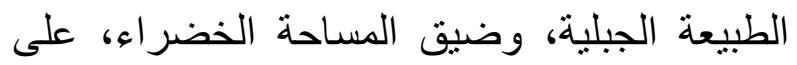

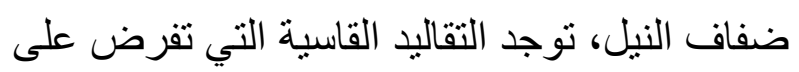

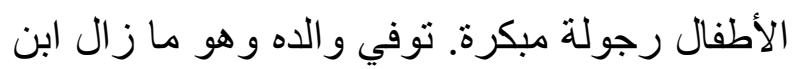

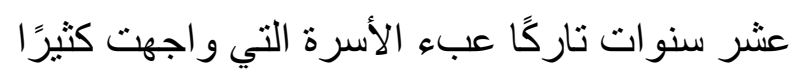

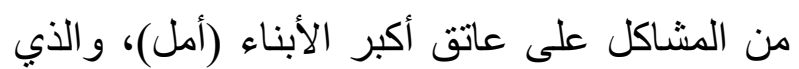

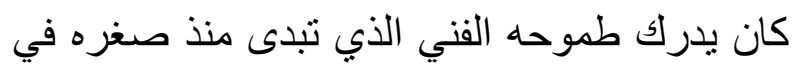

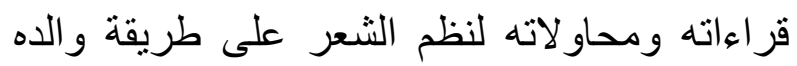

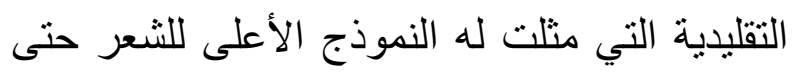

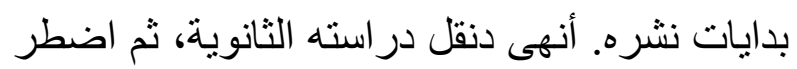

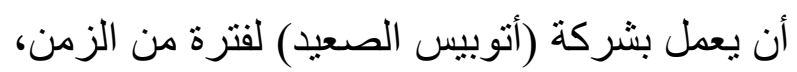

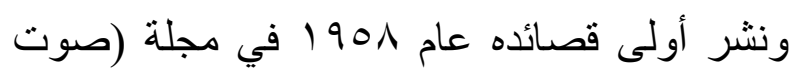
الثرق). سافر إلى القاهرة مع عدد من زملائه الذين
بعداً جوهرياً كبير أ، فإننا سوف نقف عند شاعرين:

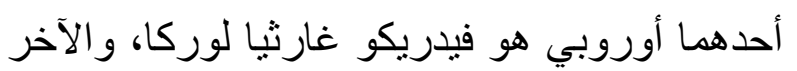

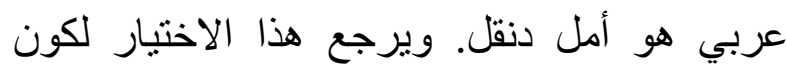

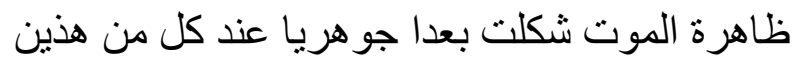

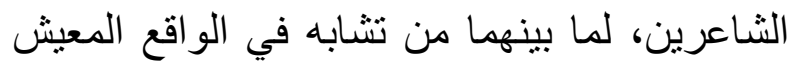

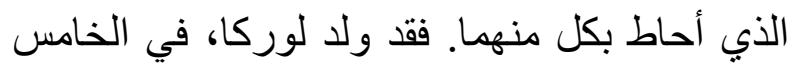

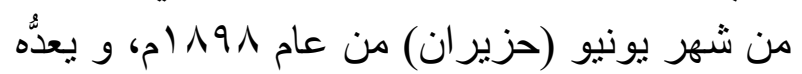

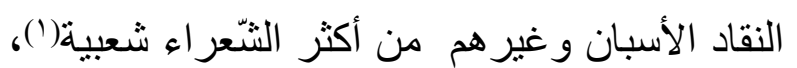

(1) وُولد "فيدريكو غارثيا لوركا" في قريةٍ إسبانيةٍِّة صغيرة تقع بقرب مدينة

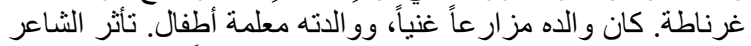

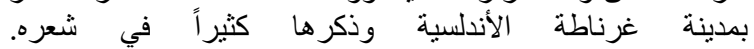

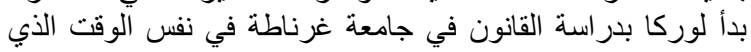

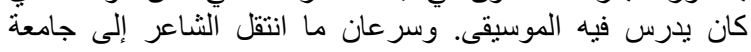
مدريد حيث تعرَّف على نخبةِ من الفنانيين مثل: الثناعر بابلو نيرودا، و الرسام سيلفادور دالي، و المخر جلئ لويس بانويل.

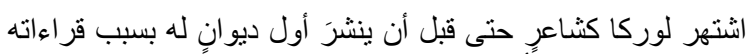

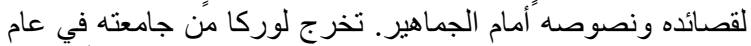

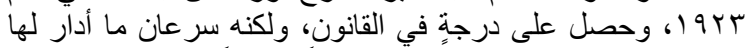

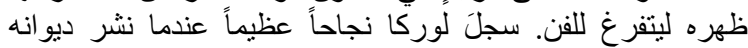

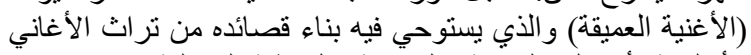
الأندلسية بأصولها العربية و الغجرية و القوطية المختلفة. و عندما نشر

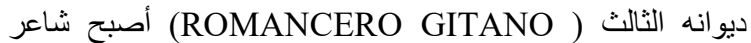

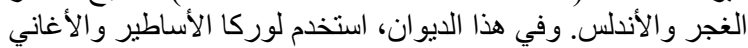

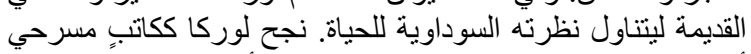

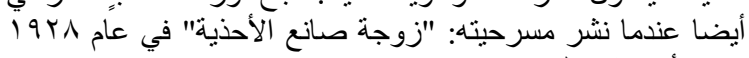
وبعد أن نشر لوركا ديوانه (PRIMER ROMANCERO GITANO)

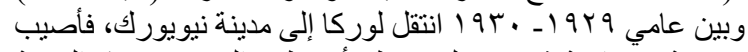

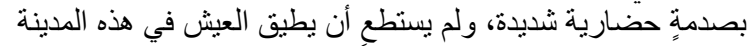

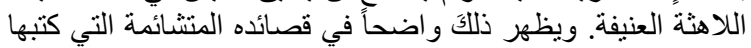

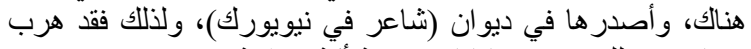

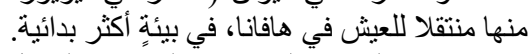

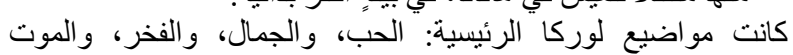

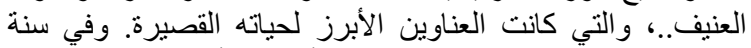

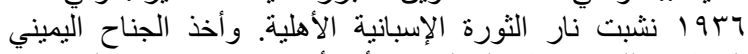

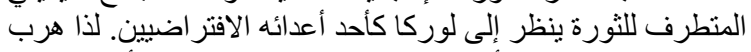

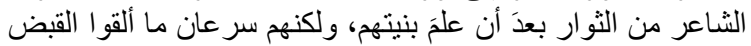

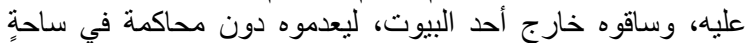

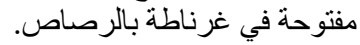
للمزيد انظر : ألموسو عة الحرة ويكيبيديا: https://ar.wikipedia.org/wiki/\%D9\%81\%D9\%8A\%D8\% AF\%D9\%8A\%D8\%B1\%D9\%8A\%D9\%83\%D9\%8 8 $\%$ D8\%BA\%D8\%A7\%D8\%B1\%D8\%AB\%D9\%8 A\%D8\%A7_\%D9\%84\%D9\%88\%D8\%B1\%D9\%83 $\% \mathrm{D} 8 \% \mathrm{~A} 7$ 
ذهنية غير مألوفة لا يعني إلا التقتح على حقول إبداعية تتطلب من العقل بذل جهد كبير، إن كان النان

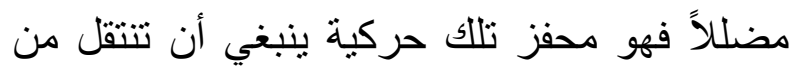
التجريد إلى الملموس، ومن الملموس إلى التجريد دون أن تقتصر على و احد من المسارين"(").

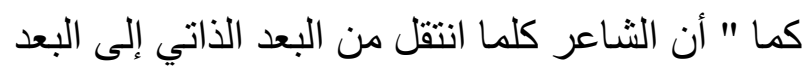

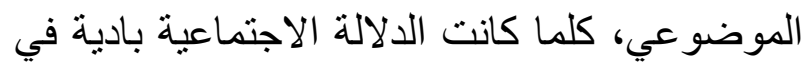
النص. فكل قصيدة من القصائد تتمتع بهذين الجانبين: الذاتي المعبر عن الحالات الثعورية والمهيئات التهاتين النفسية للذات، والموضوعي الذي يعبر فيه الثاعر

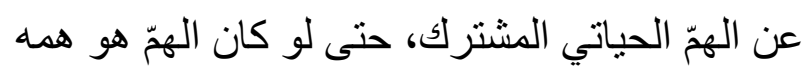
الذاتي، فهو بالتبعية يشكل بنية في نسق الهمّ المشترك الهن الهرك

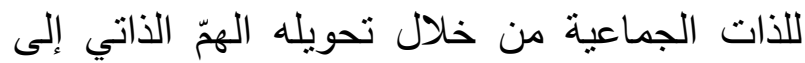

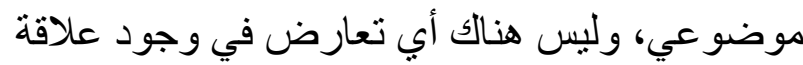

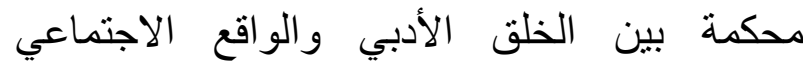
التاريخي من ناحية، وقوة الخلق التخيلي من ناحية الإدية

ثنانية"(ع).

وعلى هذا، فإن الدارس للنص الثعرى عليه استخلاص الدلالة الاجتماعية الكلية، وذلك بالنظر

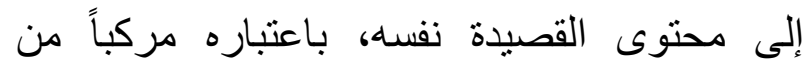

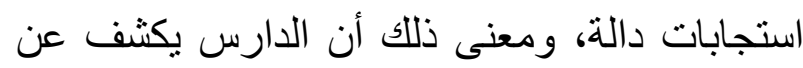
دلالات النص المتباينة الني تعينه في كثف الداني الدالة الكلية الاجتماعية للنص الثعرى. "وقد كان لوسيان جولدمان من النقاد الواعين بربط الإنيط

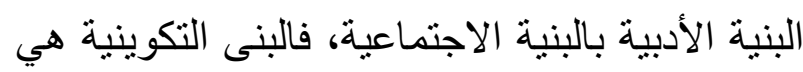

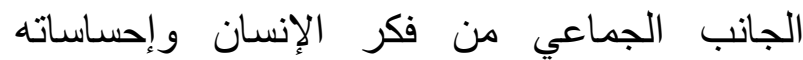

or

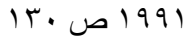

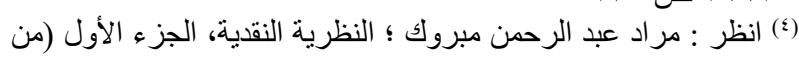

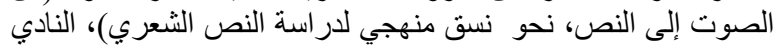

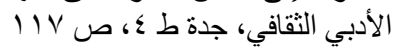

كانو ا يمتلكون الموهبة وشعروا أنهم لن يستطيعوا

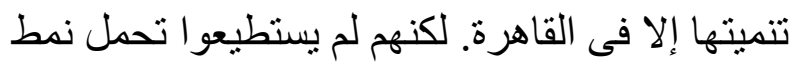

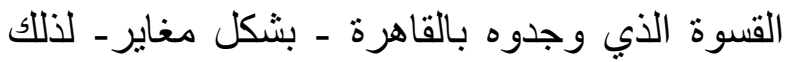
الذي اعتادوه في الصعيد، فعادو ا مرة أخرى إلى قناه

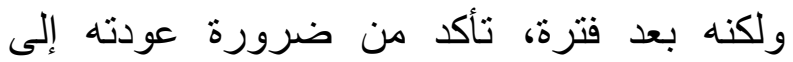
القاهرة، وهذا ما فعله، ثم انتقل إلى الإسكندرية، ومكث بها فترة، والتحق بكلية الآداب، جامعة الإنة

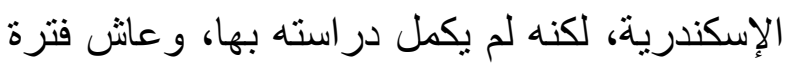
بالسويس، وكان يعمل بشركة مقاو لات هناك، ولكنه لئه

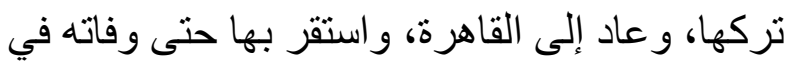

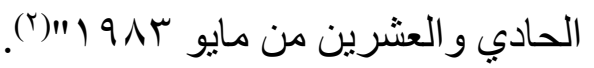

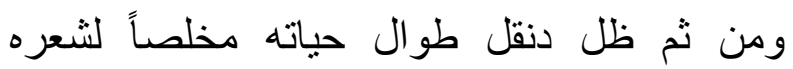
ومبادئه الإنسانية الر اقية، وكان مدافعاً عن البسطاء، وشديد الحزن والأسى على الواقع العربي المرير

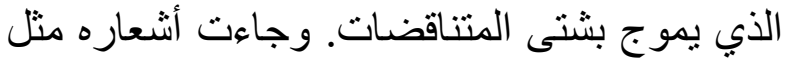
لوركا معبرة عن الو اقع ومتطلعةً لقيم الحق والعت العدل

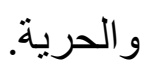

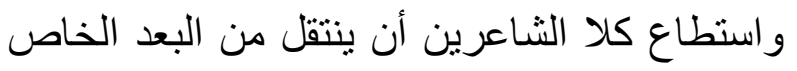

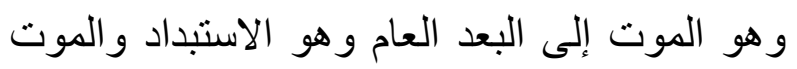
والضياع، " فالعملية الإبداعية للنصوص الإلئ الأدبية

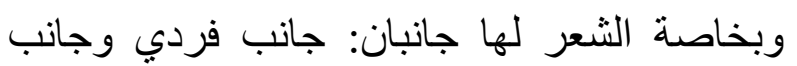

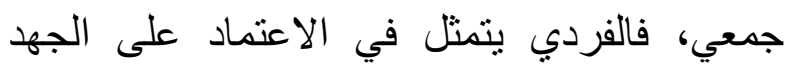

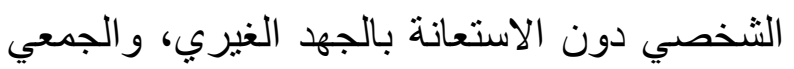

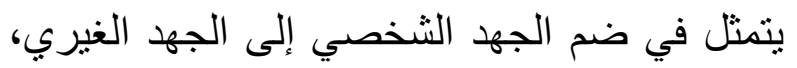

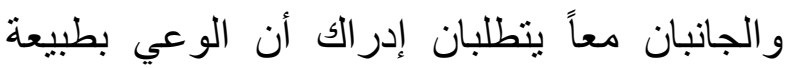

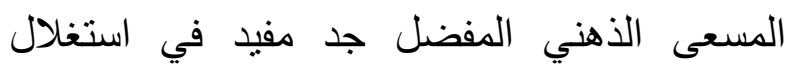

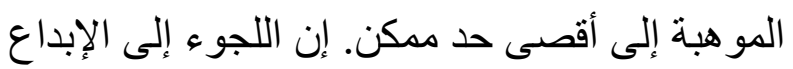
الذاتي بعيداً عن الغيري أو قريباً منه بحثاً عن مساعٍ الإعاع

(1) انظر : أمال الديب : موقع ثقافات /http://thaqafat.com/2015/05/26075 
ويرى كلود بيشو ا أن " الأدب المقارن وصف تحليلي ومقارنة منهجية تفاضلية وتفسير مركب للظاهرة اللغوية التقافية من خلال التاريخ والنقد و الفلسفة، ولفيه وذلك من أجل فهم أفضل للأدب بوصفه وظيفة تميز

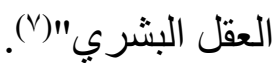
ومن ثم تأتي هذه الدر اسة لتعالج ظاهرة الموت عند كلا الشاعرين من هذا المنظور المقارن، ومن خده الثل بعض النصوص الثعرية التي برزت فيها ظاهرة الموت عندهما، وفلسفة كل منهما للموت وفق بردي المنظور الثقافي الذي شكل وعي كل منهما، ولذللك تعالج هذه الدر اسة الأبعاد الصورية المقترنة بظاهرة الموت وكيفية توظيفها والتعبير عنها عند الثاعرين.

\section{غاربا (Y) صورة الموت وتثكيل النص عند فيدريكو}

غارثيا لوركا.

إن المتأمل لشعر لوركا يجد أنه يعتمد على التشكيل الصوري أي إن الصورة تشكّل البنية المركزية في لئلئل النص الثعري، ويعني بالصورة المشاهد الصورية الصنية التي تتبلور في الذهن حال استحضار كلمات أو بوني باتهورة مشاهد النص. وهى صورة صامتة تجريدية تنتكل في وعي المتلقي - قبل النطق بها أو كتابتها - من خلال الموروث Mental" المستقر في الذاكرة، و التي بدور ها تمد النشاط الذهني بالأفكار والإشار ات الدالة ويمكن أن يطلق على هذا

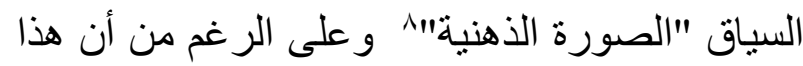

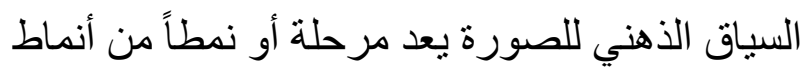

(v) انظر بديع محمد جمعة، در اسات في الأدب المقارن، دار الأندلس سنة

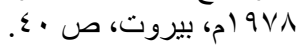

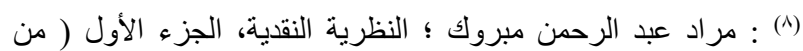

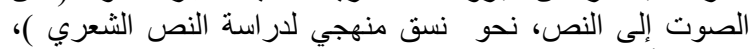

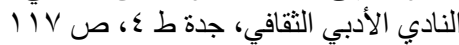

و عاداته الخُلُقِية، و لا بمكن دراسة هذه البنى بمنأى عن التاريخ. وهذا الاستنتاج يميز جولدمان عن سواه

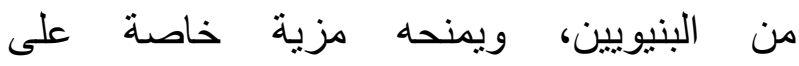

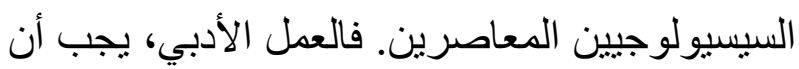

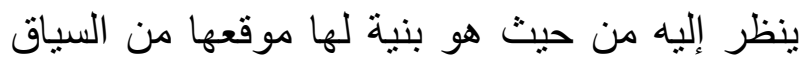

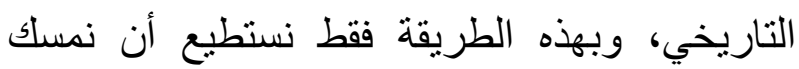

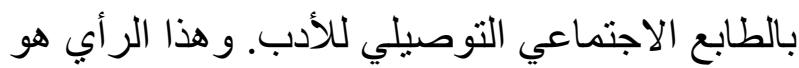

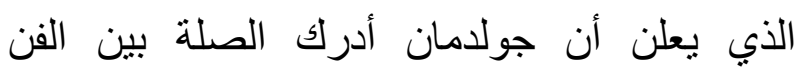

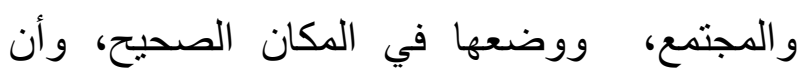
التتكر لمثل هذا الافتر اض الذي جاء به يعنى التنازل

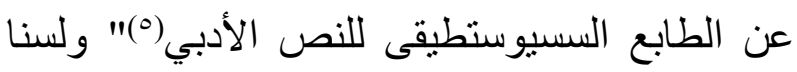
بصدد مناقثنة قضية الدرس المقارن والآراء العديدة

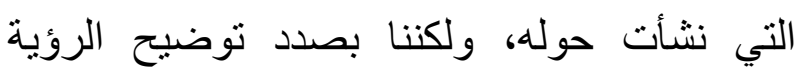
المقارنة التي انطلق منها البحث حول هذه الدراسة

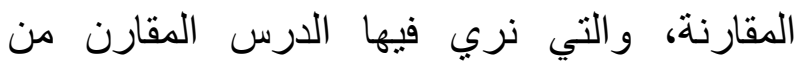

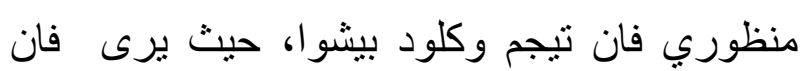

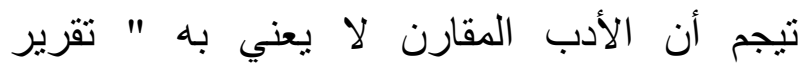

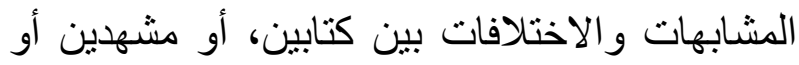

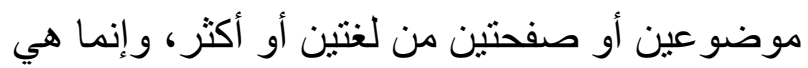

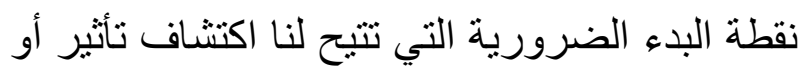
اقتباس أو غير ذلك، وتتيح لنا بالتالي أن تفسر أثراً أنتأ

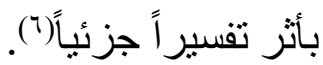

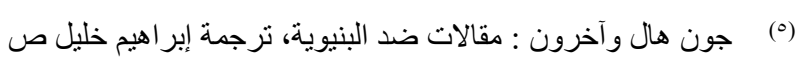

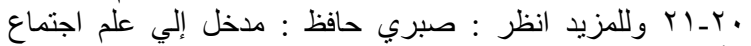

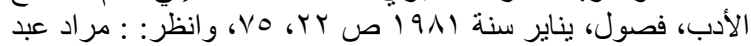

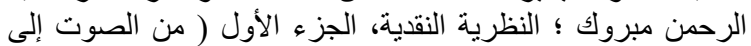
النص، نحو نسق منهجي لدراسة النص الثعرية )، النادي الأدبي

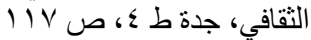

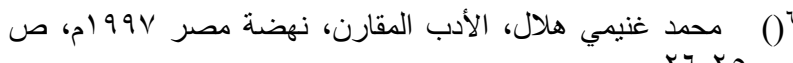

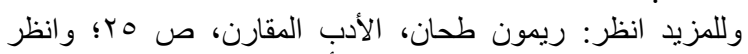

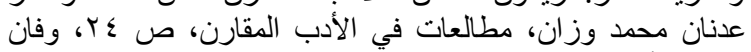

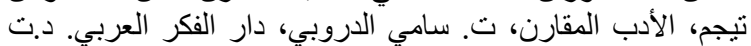

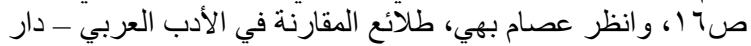

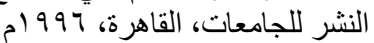


I want to sleep the dream of the apples, to withdraw from the tumult of cemeteries. I want to sleep the dream of that child who wanted to cut his heart on the high seas ${ }^{13}$. إنه يجسّد صورة الموت الذي يتربص به، ويعلم إنه

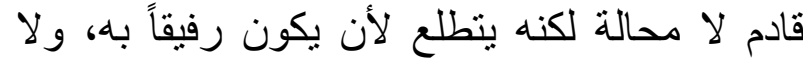
يريد زحمة القبور التي تعج حوله من كل صوب في لهاله

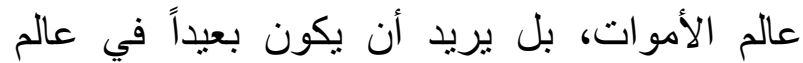

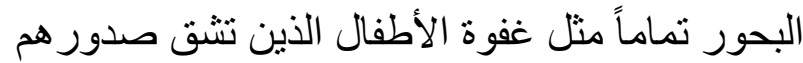
بعيداً في عالم البحار. وفي تكراره لكلمة (أريد) في الصورة الثعرية تعبير عن الحاجة الملحة لمثل هذه الأمنيات؛ لأنه يمقت حياة البؤس و الثنقاء والاستبداد التي تحيطه، حيث يتربص به الاستبداديون والقتلة و الموت يحاصره من كل مكان.

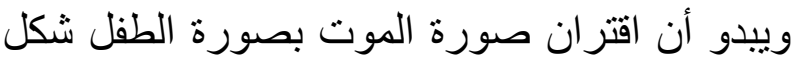
لازمة فنية في شعر لوركا فيقول في قصبيدته "

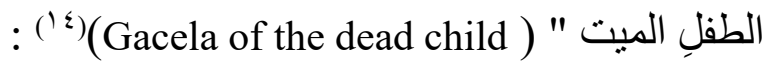

$$
\begin{aligned}
& \text { كلّ مساعٍ في غرناطة } \\
& \text { يموتُ طفلٌ كلَّ مساء. } \\
& \text { كل مساءٍ بيتربعُ الماءُ جالساً } \\
& \text { كي يتحدثَ معَ أصحابِه. } \\
& \text { الميت يلبس أجنحةً تملأها الطحالب. } \\
& \text { و الريحُ الصافية و الممطرة كانتا } \\
& \text { طاووسين حلّقا بين الأبر اج } \\
& \text { و اليومُ كان طفلاً جريحاً. }
\end{aligned}
$$

Each afternoon in Granada,

Classic Poetry Series, Federico Garcia Lorca Poems: (Tr) The world's Poetry Archives, 2004, p.7

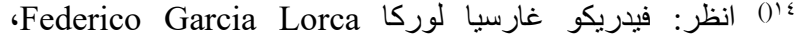

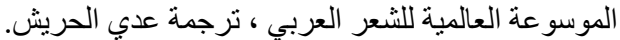
http://adab.com/world/modules.php?name=Sh3er\&doW hat $=$ shqas \&qid $=81390 \& r=\& r c=9$
تشكيل الصورة إلا أن بعض النقاد الذين بستندون إلى على النفس في رؤاهم النقدية اعتبروا أن هذا لنائ

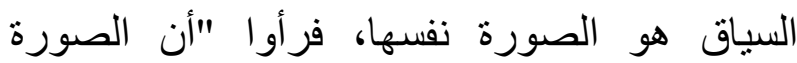
استرجاع ذهني لمحسوس."(9) أو "أن الصورة الصورة الحرة هي ما يتمثل في الذهن من صور الأشياء التي لني

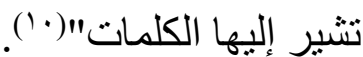
وتقول دودلى Dudley" عندما أسمع و أنا في منزلي زقزقة عصفور، أتمثل عصفوراً في عش، وأتمثل

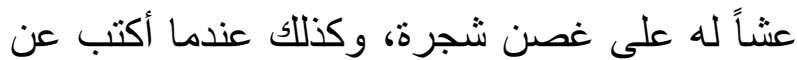

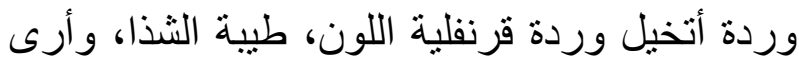
لها بضع وريقات خضر. وأقول بتعبير آخر: إنه يمكنني أن تمثل في ذهني تجربة حسية قد نلتها يوماً من غير أن يكون ذاك المحسوس قائماً قبالتي

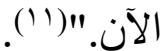

ويرجع هذا التشكيل الصوري لطبيعة المعايشة الفنية والحياتية للواقع المعيش الذي يعبر عنه كل منهما. ففي قصيدة لوركا بعنوان " الموت الأسود " نجد صورة الموت تشكل بنية مركزية فيها يقول: (r').

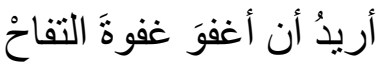

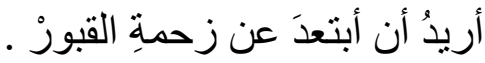

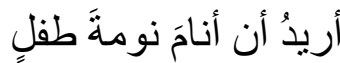

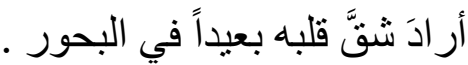

Doubleday . N .F, Studies

in poetry , Harper, New York, 1949 p . 56.

Wellek \& Warren, Theory of literature 1990

Dudley, L . : The study of literature, Hougton \& (') Mifflim, USA . 1928

و انظر أيضا : د. جابر عصفور : الصعورة الفنية في التراث النقدي و

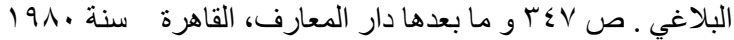

(r) انظر : فيدريكو غارسيا لوركا Federico Garcia Lorca)

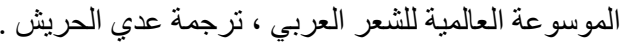
http://adab.com/world/modules.php?name=Sh3er\&doW hat $=$ shqas $\&$ qid $=81390 \& r=\& r c=9$ 
وبعد نجاحه التحق بالجامعة ليدرس الأدب و الفلسفة، وقد حدث ـ لفتوره وقلة حماسته خلال هذه المرحلةـ

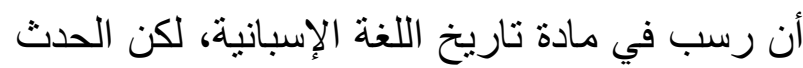
لم يمر في صمت، كما يحدث مع غيره، فأساتذته استاؤو ا منه كثير ا، و أصدقاؤه استغربوا لما لما يعرفونه عنه من ذكاء حاد وذاكرة قوية يحسد عليها...أما الصحفي ج.م غانيدو فقد كتب مقالة، لنقل عنها مقالة تنبئية؛ ينبه فيها أساتذته هؤلاء إلى مكانة لوركا

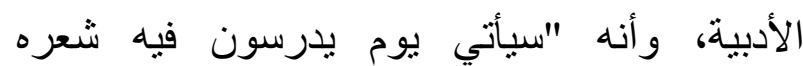
ويفسرونه من فوق منابر هم تلاكل...". وهذه النشأة

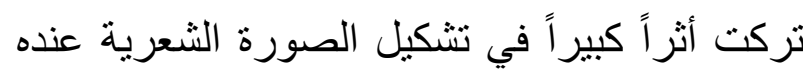

ولعل الطفل رمز المستقبل أصبح في وعي لوركا ينذر بضياع المستقبل في واقع تتضاءل فيه قيم الحق ولى و العدل و الحرية. - ملية

فكل مساء يموت الأطفال غرفا بينما ماء البحر الذي ابتلع أجسادهم الغضة ونزع أرو احهم البريئة لا يعبأ بشيء، إنه أثبه بالسلطة المستبدة التي تزهن هن أرواح

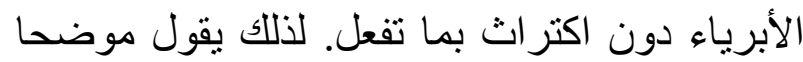

هذه الرؤية في القصبدة نفسها (1^) لم يبقَ حتى رفرفة قنبرةٍ في السماء

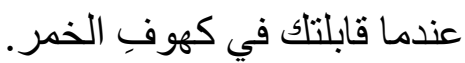

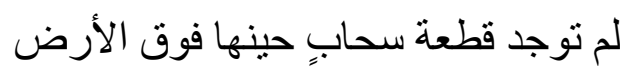
عندما غرقتَّ وسط النهر. عملاق المياه تمدد فوق التلة

$8 \% \mathrm{D} 8 \% \mathrm{BA} \% \mathrm{D} 8 \% \mathrm{~A} 7 \% \mathrm{D} 8 \% \mathrm{~B} 1 \% \mathrm{D} 8 \% \mathrm{AB} \% \mathrm{D} 9 \% 8$ A $\%$ D8\%A7 \%D9\%84\%D9\%88\%D8\%B1\%D9\%83 $\% \mathrm{D} 8 \% \mathrm{~A} 7$

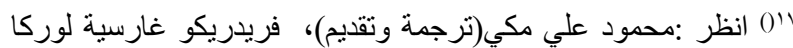
Federico Garcia Lorca الأول، المجلس الأعلى للثقافة، الطبعة الأولى 991 ام، ص 9

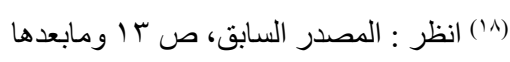

each afternoon a child dies.

Each afternoon the water sits down and chats with its companions.

The dead wear mossy wings.

The cloudy wind and the clear wind, are two pheasants in flight through the towers and the day is a wounded boy. ${ }^{(10)}$

إن صورة الموت واقتر انها بالطفل لاسيما الموت غرقا تشكل لازمة في شعر لوركا، وربما يرجع هذا للنشأة

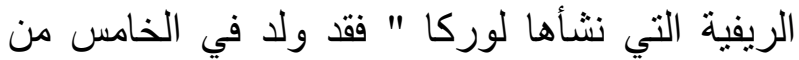

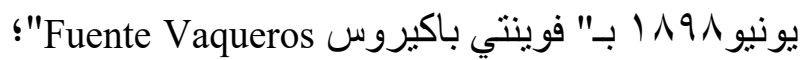
وهي قرية صغيرة تبعد عن غرناطة، بعشرين كيلومترا، من أب فلاح وأم مدرسة أدخلته إلى عالم المعرفة في سن مبكرة. كان و الده يمتلك في تلك المنطقة الفلاحية الخصيبة أر اض زر اعية وضيعات...وسقط في في وني

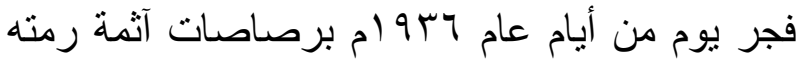
بها بنادق كتائبية حاقدة، خارج غرنام عاطة؛ في منطقة "بيثنار Viznar"تحت أشجار الزيتون؛ قرب نافورة، وهو لم يكمل عقده الرابع. و وتلقى در استه في قريته ثم

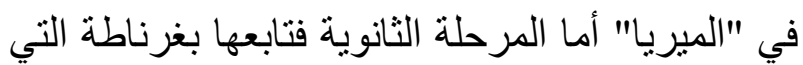
كانت أسرته قد انتقلت إليها؛ غير أنه لم يظهر اهتماماً بدر استه، فقد كان همه الأكبر منصباً على القر اعة الحرة وكتابة الأشعار إلى جانب العزف على البيانو، البه مما كان

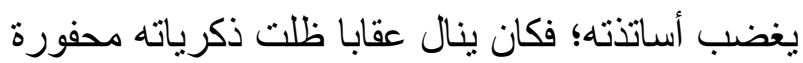
في أعماقه وفي كراسة يومياته: "إنني أعرف الكثير

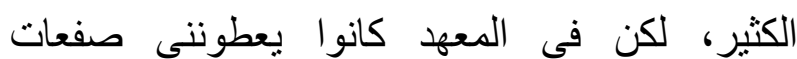
هائلة..." (17).

Classic Poetry Series, Federico Garcia Lorca (10) Poems: The world's Poetry Archives, 2004, p. 8 (1) (للمزيد انظر : الموسو عة الحرة، ويكيبيديا: https://ar.wikipedia.org/wiki/\%D9\%81\%D9\%8A\%D8\% AF\%D9\%8A\%D8\%B1\%D9\%8A\%D9\%83\%D9\%8 
الخاص. ومن ناحية أخرى، فإن التعبير عن النفس

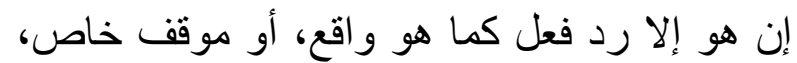

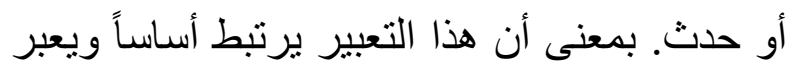

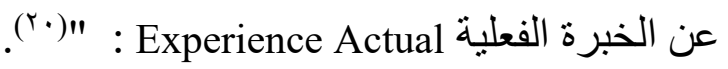
و هناك قصائد عديدة نجد فيها صورة الطفل و اقتر انه : Exp

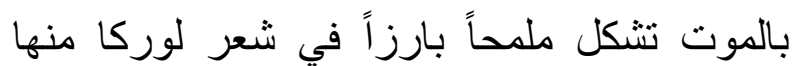
أيضا قصيدة " حي من قرطبة "(r)". إنهم يحتمون في البيت

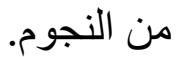

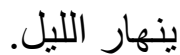
في الداخل، هناك طفلة ميتة ووردة حمر اء، مخبأة في شعر ها. فيكيها ست بلابل في الشبالك الحديدي. بتتهد الناس وقيثار اتهم ناحبة.

they shelter'Inside the house

from the stars

night tumbles down

Inside a dead young girl

A crimson rose

hidden in her hair

Six nightingales mourn for her

Behind the bars

People sigh and sigh

With open-mouth guitars ${ }^{(r)}$

(r·(r)(انظر سوزان لانجر : فلسفة الفن إعداد راضى حكيم، دار الثئون

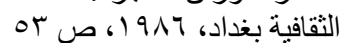

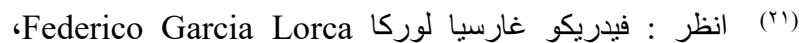
الموسوعة العالمية للشعر العربي ، ترجمة عدي الحريش. http://adab.com/world/modules.php?name=Sh3er\&doW hat $=$ shqas \&qid $=81390 \& r=\& r c=9$

Tem Chilcott, Federico Garcia Lorca Poema Del $0^{\text {rr }}$ Cante Jondo, Poem of the deep Song (translated): PARALLEL TEXT, 2007, p.7

$$
\begin{aligned}
& \text { النهر يلهو بالكلابِ و الزنابق. } \\
& \text { جسملكَ بين ظلالِ بداي البنفسجية }
\end{aligned}
$$

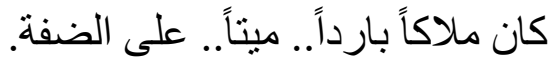

Not a flicker of lark was left in the air when I met you in the caverns of wine. Not the crumb of a cloud was left in the ground when you were drowned in the river. A giant of water fell down over the hills, and the valley was tumbling with lilies and dogs.

In my hands' violet shadow' your body, dead on the bank' was an angel of coldness ${ }^{19}$

عندما تحول الموت إلى شبح يطارد الأبرياء يحلق في السماء بجناحيه ممثنا في الطاووسين اللذين انبثقا من الظواهر الكونية (كالرياح العاصفة، والممطرة،

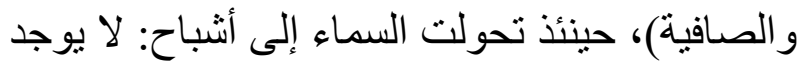
فيها صوت زقزقة، أو حركة، أو همسة لعصفور صغير، إلا صورة الطفل الغريق تطفو فوق الماء، و المياه تتحول لكائن خر افي عملاق بتمدد فوق التالال ليبتلع كل ما حوله. على حين أن النهر المستبد لا يعبأ بالموت أو الطفولة

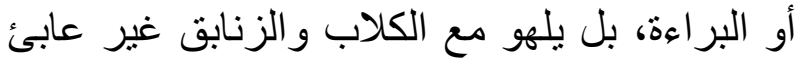
بشيء، و الثاعر يوسد جسد الطفل بين ذر اعيه وهو

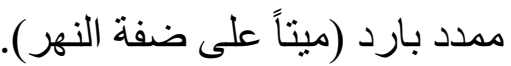

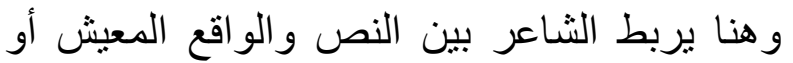

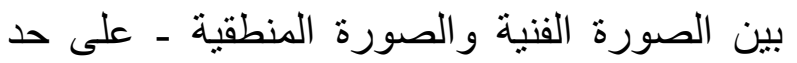
تعبير سوزان لانجر - من حيث إن هناك تشنابهاً أو تماثناً في العلاقات بينهما، و على هذانى هذا يكون التعبير منطقياً من حيث الثكل و العلاقة والترابط: "ولأن هئن الفن يختلف عن المنطق، فإن للصورة منطقها

Classic Poetry Series, Federico Garcia Lorca Poems: The world's Poetry Archives, 2004, p.8 
والإسمنت و الحديد إنسانية الإنسان وتمسخ روحه،

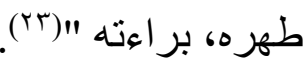
ولعل هذا يثكل الدافع الأكبر لتوظيف لوركا لصور

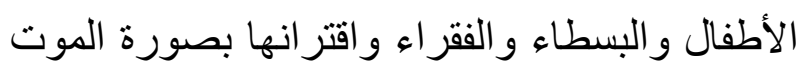
في أشعاره للتعبير عن الواقع الإنساني المعيش.

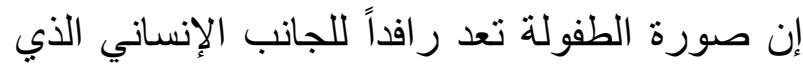

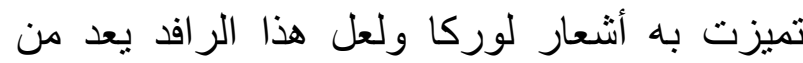

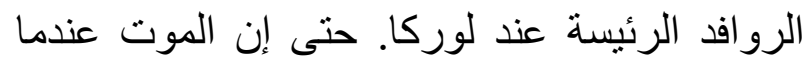
يقترن بالثاعر ذاته يعبر عن هذه الصورة مفترنة

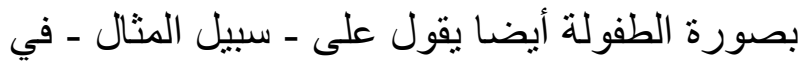

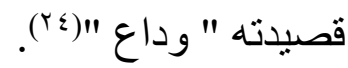

$$
\text { عندما أموت }
$$

أتركِ الثرفة مفتوحة

الفتى الصغير يأكل البرتقال (أستطيع رؤيته عبر شرفتي) باحني

المزارع بحصدُ القمح

(أستطيع سماعه عبر شرفتي)

عندما أموت

أتركِ الثرفة مفتوحة! (Farewell)

If I die، leave the balcony doors

Federico Garcia انظر : حول التعريف بفريدريك غارسيا لوركا العربكا (Wr) Lorca http://adab.com/world/modules.php?name=Sh3er\&doW hat $=$ shqas $\&$ qid $=81390 \& r=\& r c=9$

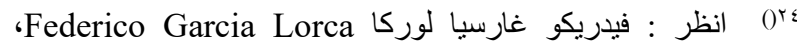

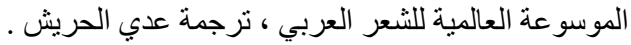
http://adab.com/world/modules.php?name=Sh3er\&doW hat $=$ shqas $\&$ qid $=81390 \& r=\& r c=9$
إن صورة الموت عند لوركا تأخذ بعداً إنسانياً عميقاً في قصائده الثعرية. فقد كان شديد الإحساس و الثعور بحياة الفقراء و البسطاء و المعدمين في كل

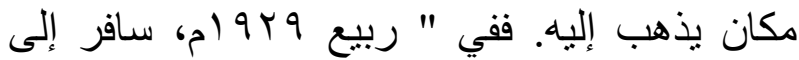

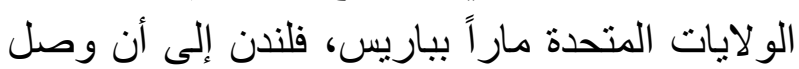

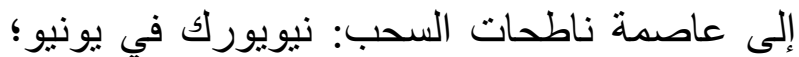

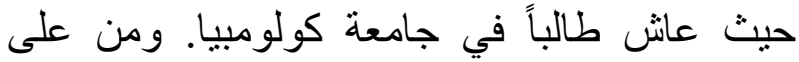

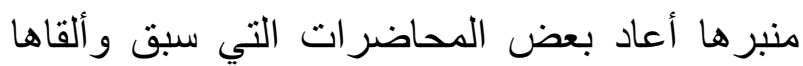
بإسبانيا، ولحّن بعض الأغاني التي استمد روحها من التصن الموشحات الأندلسية ومن الفيلامنكو إلى المغنية الفنية "أنطونيا ميرثي Antoňia Mirce" ومن بينها لالانيا "الطحانون الأربعة" و "الحاجان الصغيران". ولما ولانيا كانت روحة التو اقة دوما إلى الحرية، إلى الانطلاق،

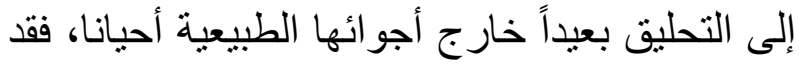

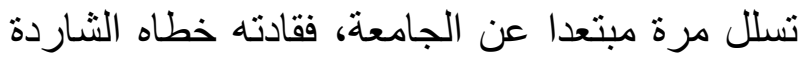
إلى حي "هارلم"؛ الوجه المشوه والبشع لـدينة

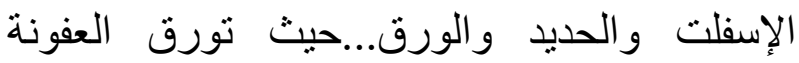
ويزهر البؤس والفقر ... وحيث تنقتح عوسجات القتل المجاني، وتتأكسد التناقضات، وتتناسل وتتكاثر الخنافس الإليكترونية في فضاءات الصخب الأسود، وحيث تتفجر أنهار الدم والعرق من أنشلاء أجسام

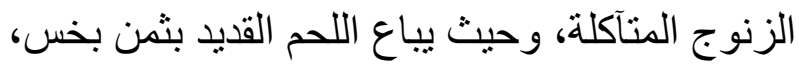
ويدرك الأطفال لحظة الولادة أن لا فردوس هناع الك الك ولا حب مجرد، ويعرفون أنهم إلى وحل الأرقام

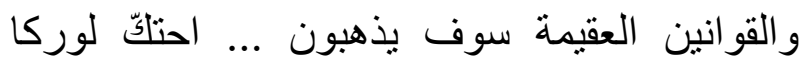

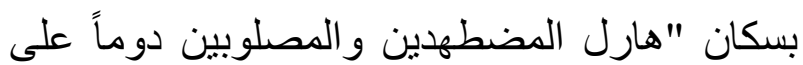
أسنة الحياة، وعايش فقر هم الزنجي، و لاعب الأطفال ... عاش حياتهم المريرة ورأى عذاباتهم السيزيفية اليومية، فأحس كأنه في غابة تأكل ذئابها خرفانها الوديعة، ورأى كيف تحول المادة الإنسان إلى آلة، إلى رقم، إلى لا شيء ... وكيف تقتل مدينة الورق الإن الكية 
القصائد تعبر عن هذه الرؤية نذكر منها قصبيته " فقر ات من كتاب الموت" التي يقول فيها (־؟r):

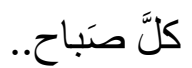

أفتحُ الصنبورَ في إرهاتِ

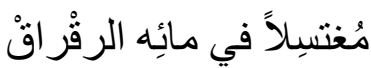

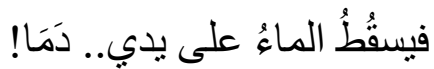

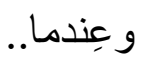

أجلسُ للطّعام.. مُر غما:

أبصرُ في دوائر الأطباقْ

جماجِماً.

جماجماً.

مفغورةً الأفو اهِو والأَحداقْ!!

لعل صورة الموت عند أمل اقترنت بالعنف و الدماء

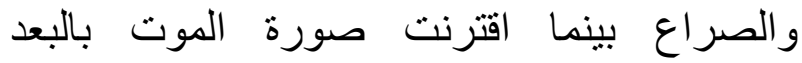
الإنساني عند لوركا، ومن ثم كانت الصورة أكثر هدوءاً وأقل عنفاً، على الرغم من أن الموت واحد عند كليهما. ويرجع هذا لطبيعة الصراع المحيطة بكل منهما فعند أمل دنقل مبعث الصرئ هراع استبداد

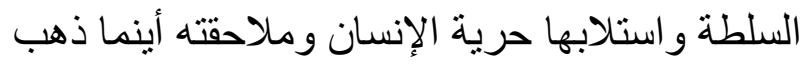
نتيجة شيوع قيم الفساد والاستبداد ولذلك يقول في القصيدة نفسها(rV) أحفظٌ رأسي في الخز ائنِ الحديديّة و عندما أبدأُ رِحلتي النهاريّة أحمل في مكانِها.. مذياعا!

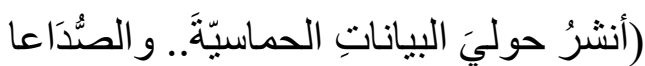
وبعد أن أعودَ في خِتامِ جولتي المسائيّة أحمل في مكان ر أسي الحقيقيّة

PrT (انظر: أمل دنقل، الأعمال الثعرية الكاملة، مكتبة مدبولي، القاهرة:

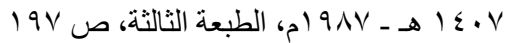

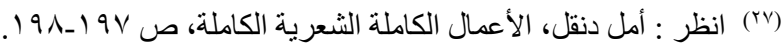

open.

A boy eats oranges.

(From my balcony، I see him.)

The reaper reaps the wheat.

(From my balcony، I'm sorry to hear him.)

leave the balcony doors 'If I die open! ${ }^{\left(r^{\circ}\right)}$

و هكذا نجد أن صورة الموت عند لوركا تتسم ببعض الخصائص أبرزها؛ اقتران صورة الموت بالطفولة، وكأن أشرار البشر والمستبدين يغتالون الطفولة و البراءة و النقاء في كل عصر ، ليست الطفولة فحسب البن ولكن كل فعل يقترن بها. ومن هذه الخصائص أيضاً اقتران الموت بعل بالبعد الإنساني للتعبير عن عذابات الفقراء والبسطاء في كل المدن و العو اصم و البلدان المختلفة. فضلان عن أن أن صورة البحر اقترنت بالموت والغرق والضياع في وني معظم قصائده، وكلها تعبر عن تطلع الثاعر للحرية والحق و العدالة وتخفيف الآم البسطاء ومؤازرتهم. أي أننا نستطيع القول: إن صورة الموت أخذت بعدا إنسانياً عميقاً في شعر لوركا.

(r) صورة الموث وتثكيل النص عند أمل دنقل إذا كانت الرؤية الفكرية عند لوركا قد اقترن فيها الموت بالرؤية الإنسانية، فإن الرؤية الفكرية للصورة عند أمل دنقل اقترن فيها الموت بالرؤية الحياتية العربية

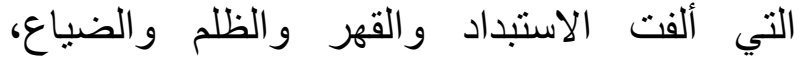
و التناقض بين: ما هو كائن، وما يجب أن يكون. ويبدو أن تعبيره عن الموت ليس وليد المرحلة الأخيرة من حياته المرضية التي انتهت بموته و عبر عنها في ديوانه (أوراق الغرفة م) لكنه وليد معايثته هينه

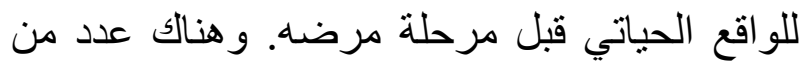

Classic Poetry Series, Federico Garcia Lorca Poems: ${ }^{\left({ }^{\circ}\right)}$ The world's Poetry Archives, 2004, p 6 
عن الفم المحثِّ بالرمال و الدماء!! إن الموت هنا يرتبط بالصر اع السياسي و العسكري بين العرب و إسرائيل عامة، ومصر و والكيان

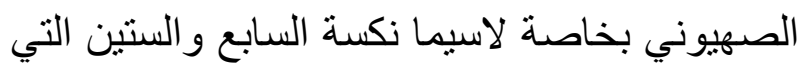

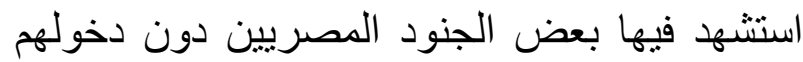
معركة لخلل في الاستر اتيجية العسكرية آنذاك. ولكن مبعث الموت في حقيقته منظومة الخلل التي تقود المجتمع حيث التباين الطبقي والاجتماعي وانسحاق البسطاء وتقدمهم ميادين القتال بينما من ون لهن ينهبون ثروات الوطن هم أكثر المجتمع بعدا عن وناءن

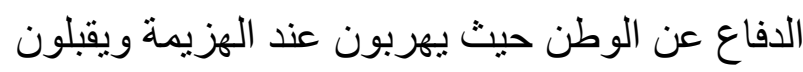

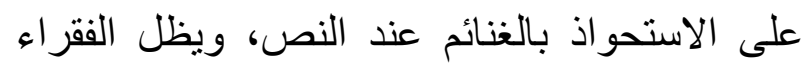

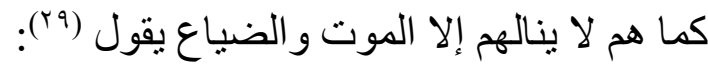

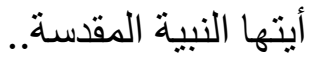
لا تسكتي.. فقد سَكَتُُّ سَنَةً فَسَنَةً.. لكي أنال فضلة الأمانْ قيل ليَ "اخرسن.". فخرستُ.. و عميت. . و وائتممتُ بالخصيان!

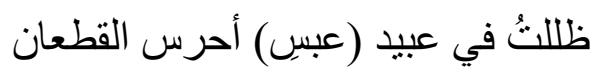

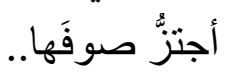

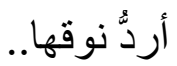

أنام في حظائر النسيان طعاميَ: الكسرةُ.. و الماءُ.. وبعض النّان الثمر ات اليابسة. وها أنا في ساعة الطعانْ

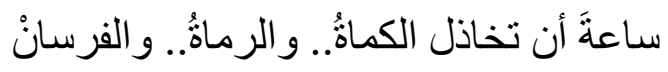
ذُعيت للميدان!

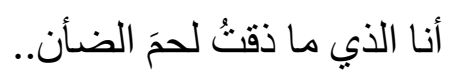
أنا الذي لا حولَ لي أو شأن..

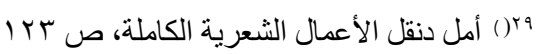

قنتينيةَ الخمرِ الزُجاجيّة! أعوذُ مخمور آ الى بيتيَ.. في الليلِ الأخيز

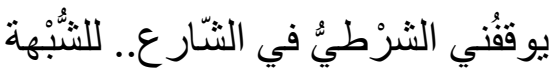
يوقفُني.. بر هة! وبعد أن أرشُوَهُ.. أو اصل المهبر إن الموت عند أمل دنقل مبعثه شعور الذات الذات الإنسانية بالانسحاق و الضياع وانتشار الفساد و التضليل، فقد

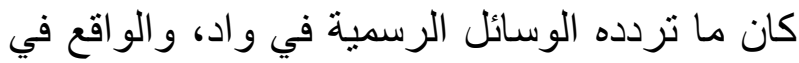
واد آخر، الأمر الذي يجعله يشعر بالأسى والحزن الدئن

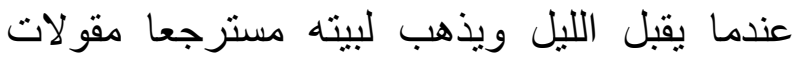
الكذب والتضليل التي تلوكها الألسنة صباح مساء، و هي بعيدة عن الحقيقة. وتتضح هذه الصورة أكثر في قصيدنه " البكاء بين

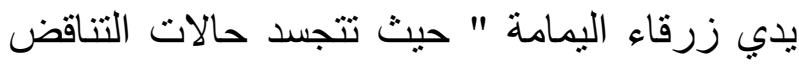
بصورة أكبر بين: ما هو كائن، وما يجب أن يكون، لئه يقول فيها (r^) أيتها العر افة المقدَّسنْ... جئُ إليك.. مثخناً بالطعنات و الدماءُ

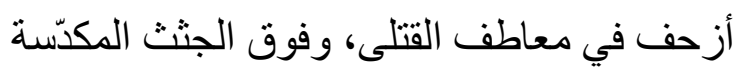
منكسر السيف، مغبَّر الجبين والأعضاء.

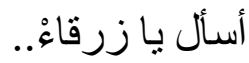
عن فملكِ الياقوتِ عن، نبو عة العذر اء عن ساعدي المقطوع.. وهو ما يز ال ممسكاً بالر اية نوة المنكَّسة عن صور الأطفال في الخوذات.. ملقاةً على الصحر اء عن جاريَ الذي يَهُمٌُ بارنتشاف الماء.. فيثقب الرصاصن رأسَهَ.. في لحظة الملامسة بـأ

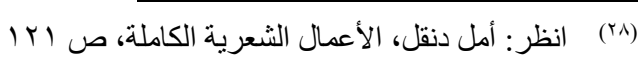


هنا يأخذ الموت بعدا أكثر عمقاً، ويقترب من صورة

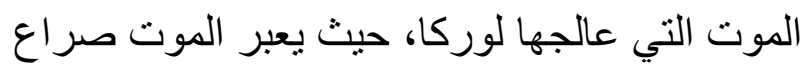

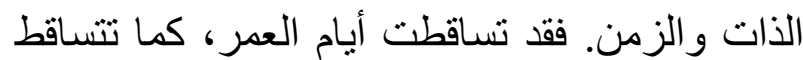

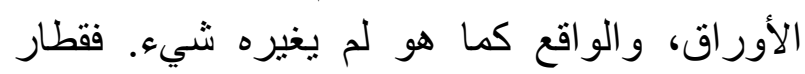

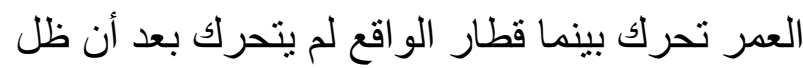

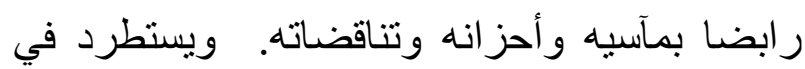
اللوحة الثانية للموت فيقول في القصيدة نفسها (بآ): شقيقتي " رجاء " ماتت وهي دون الثالثة. ماتت وما يز ال في دو لاب أمّي السّري صندلها الفضنيّ! صدير ها المشغول، قرطها، غطاء رأسها الصنّوفيّ أرنبها القطنيّ! و عندما أدخل بهو بيتنا الصامت فلا أر اها تمسك الحائط.. علّها تقف أنسى بأنّها ماتت. أقول. ربّما نامت. أبحث عنها في الغرف. رئ. و عندما تسألني أمّي بصوتها الخغرف الخافت أرى الأسى في وجهها الممتقع الباهت و أستبين الكارثة! الاست وفي

إن الذات تستحضر الموت مجسداً في صورة أخته

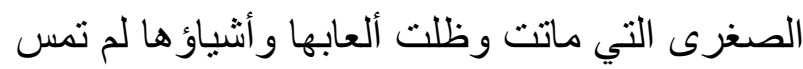

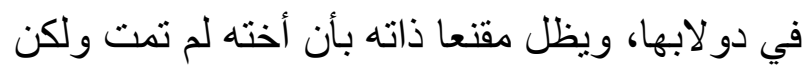
عندما يلحظ الحزن والأسى في وجه أمه يداك يدرك

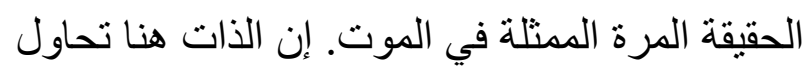
رفض الموت على الرغم من كونه حقيقة مرة و اقعية

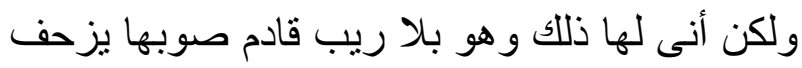

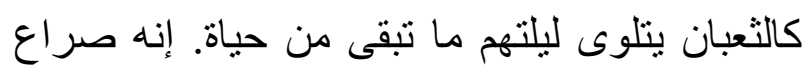

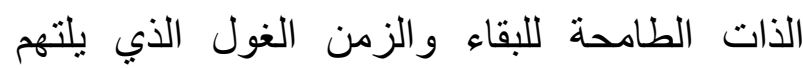

أنا الذي أقصيت عن مجالس الفتيان، أدعى إلى الموت.. ولم أدع الى المجالسة!!

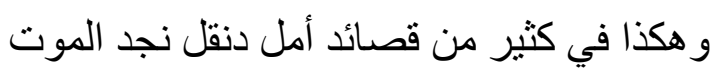

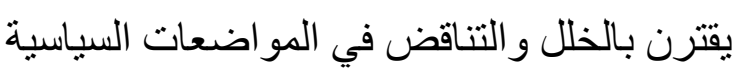
و العسكرية والاجتماعية و الاقتصادية بين ما هو كائن وما يجب أن يكون. $* * * * * * * * * *$

على أن هذه الرؤية تتطور في مرحلته الأخيرة عندما

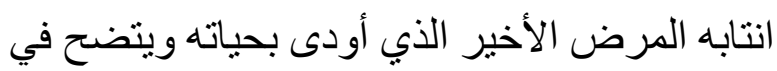

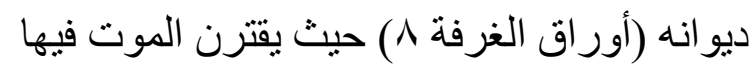

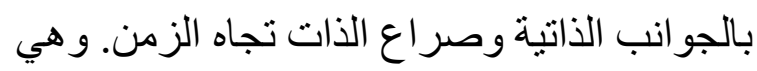

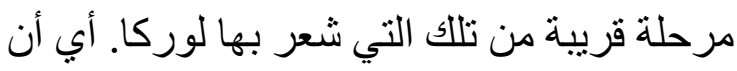

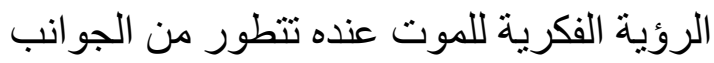
السياسية والاجتماعية إلى الجو انب الإنسانية و الفلسفية، يقول في قصيدته الموت في لوحات (·r): مصفوفةٌ حقائبي على رفوف الذاكرة و السفر الطويل.. يبدأ دون أن تسير القاطرة! رسائلي للثمس. تعود دون أن تمسّ! رسائلي للأرض..

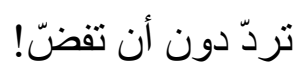
يميل ظلّي في الغروب دون دون أن أميل! وها أنا في مقعدي القانط. وريقة.. وريقة.. يسقط عمري من نتيجة الحائط والورق الساقط يطفو على بحيرة الذكرى، فتلتوي دو ائر ا وتختفي.. دائرة.. فدائرة! 
قمصانه المغسولة البيضاء تنشر حولها نقاء قلبها الهانئ

$$
\text { و هي تروح وتجيء }
$$

والآن بعد أشهر الصيف الرديء

رأيتها.. ذابلة العينين و الأعضاء

تنشر في شرفتها على حبال الصّمت و البكاء

$$
\text { ثيابها السوداء! }
$$

ما يز ال الموت يصرع الذات في هذه اللوحة الشعرية وترتدي المحبوبة لون الحداد و الصمت يغلف جو انب

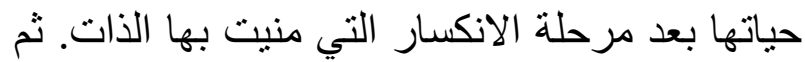
تأتي اللوحة الخامسة للموت عند أمل دنقل لتجسد التهدي

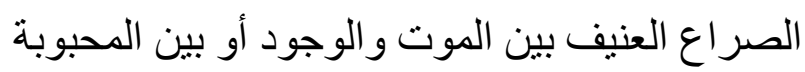
رمز الخصب والتجدد والحياة وبين لحظات الموت لهوبن

$$
\text { و الانكسار و الضياع يقول (ء): }
$$

حبيني في لحظة الظلام؛ لحظة التو هّج العذبة تصبح بين ساعديّ جثّة رطبة!

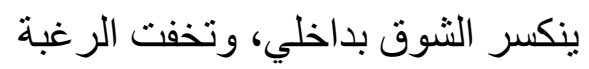
أموء فوق خدّها أضر ع فوق نهدها أودّ لو أنفذ في مسامّ جلدها لكن.. يظلّ بيننا الزجاج.. و الغياب... و الغربة!

وذات ليلة، تكسّرت ما بيننا حو اجز الرّ هبة فاحتضنتني.. بينما نحن نغوص في فرات مار التربة تبعثرت في رأسها شرائح الصورة و النجوم واختلطت في قلبها الأزمنة الهشيم

گ
الأرواح. لكن الموت في النهاية هو صاحب الغلبة

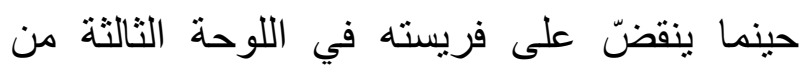
القصيدة نفسها حيث يقول (rr) عرفتها في عامها الخامس و العشرين

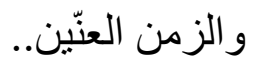

ينشب في أحشائها أظفاره الملويّة

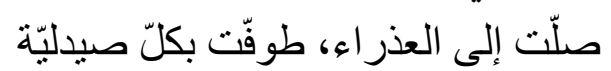
تقلّبت بين الرجال الخثنين! وماتز ال تشتري اللّفائف القطنيّة؛! ما تز ال تشتري اللّفائف القطنيّة! وحين ضاجعت أباها ليلة الرعد تفجّرت بالخصب و والو عد

و اختلجت في طينها بشارة التكوين! لكنّها نادت أباها في الصباح.. فظلّ صامتا! هزّته.. كان ميّتا!!

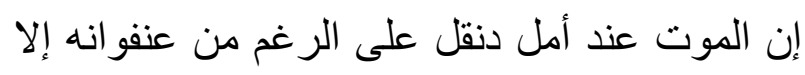
أن الميلاد يتفتق من رحمه، هذه الصورة المجسدة للصراع بين الذات والزمن تشكل ملمحا بارزا في لني ديوانه " أوراق الغرفة م لين لمن ومن رحم الموت تولد الحياة وتتخلق بشارة التكوين. ويستمر الصراع بين الذات والزمن مجسدا في لوحات الموت فيقول في اللوحة الر ابعة وبن من شرفتي كنت أر اها في صباح العطلة الهادئ تنشر في شرفتها على خيوط النور و الغناء ثياب طفليها، ثياب زوجها الرسميّة الصفر اء فئ

101.

(rr) انظر : أمل دنقل الأعمال الشعرية الكاملة، ص 101 
ويرجع هذا إلى أن " معظم صور المفارقة تتبع من رؤيتين: الأولى : هي الدهنة التي التي تهز مشاعر

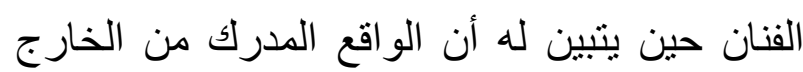

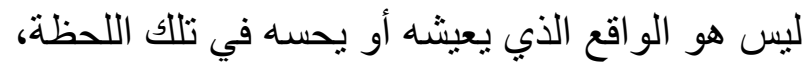

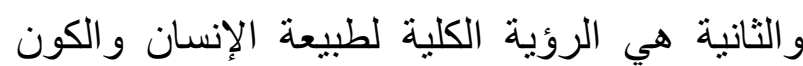

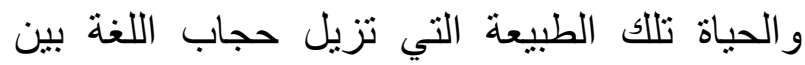

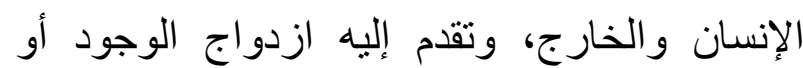
التضاد القائم فيه على الأقل من ناحية الثعور ."("ج"ج).

\section{خاتمة}

فقد استطاعت هذه الدراسة أن تعقد مقارنة نطيقية

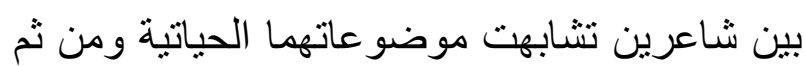

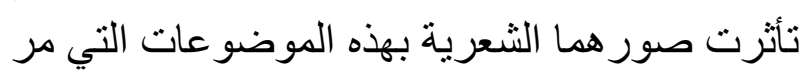
بها كل منهما، وكانت صورة الموت علئ عاملاً مشتركاً بينهما على مستوى الرؤية الفكرية والأداة التعبيرية

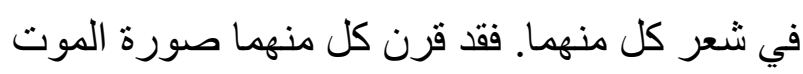

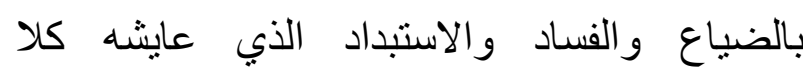

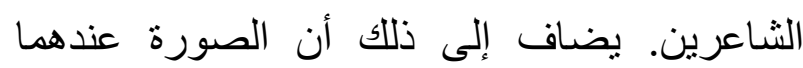

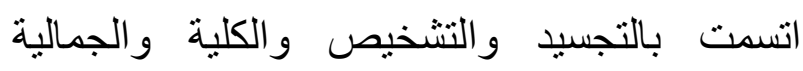

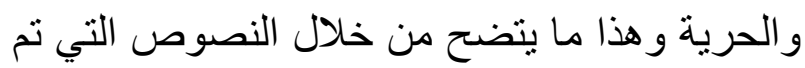

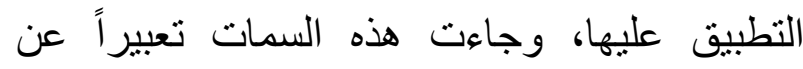
الو اقع الذي جسّد الرؤية الإبداعية عند الثناعرين.

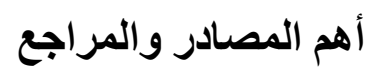

أولاً: المصادر والمراجع العربية

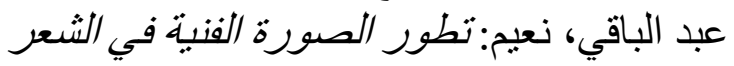
العربي الحديث، منشور ات اتحاد الكتاب العربي، العيك

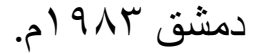

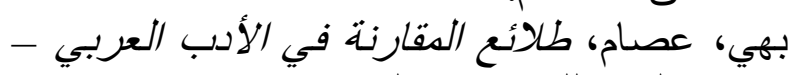
دار النشر للجامعات، القاهرة، 997 أم. 99 المان

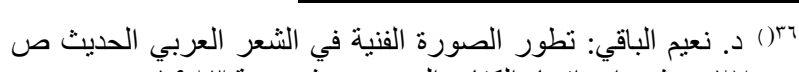

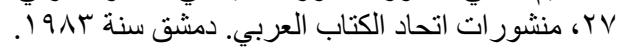

$$
\begin{aligned}
& \text { لكنّهاو وهي تناجي } \\
& \text { سمعتها تناديني } \\
& \text { باسم حبيبها الذي قد حطّم اللّعبة } \\
& \text { مخلّفا في قلبها.. ندبة!! }
\end{aligned}
$$

إن الذات تحاول التظلب على كافة الحواجز الزمنية الممثلة في الزجاج و الغياب و الغربة والصعاب حتى الصى الصن يولد الميلاد الجديد، وتحاول الذات ولنات تحطيمها من خلال الخصوبة والتجدد و الحياة والتوحد بالمحبوبة التية

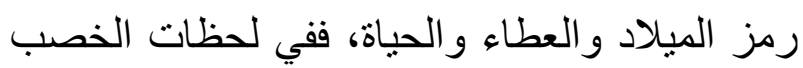

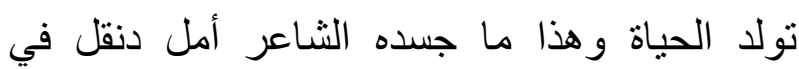
لوحاته برؤية فكرية و إبداعبة واعية. لكن الثاعرين يتفقان في حركية الصورة الثية الثعرية

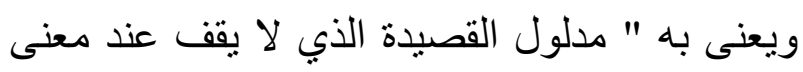

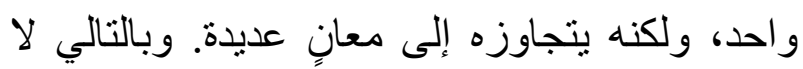

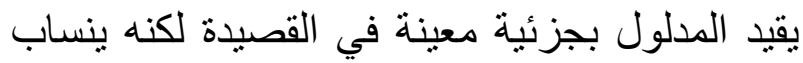

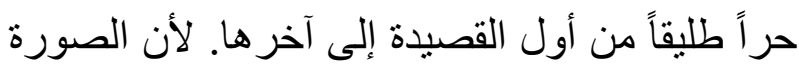

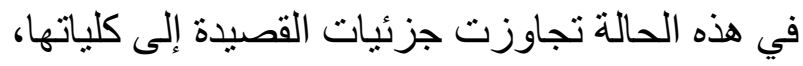

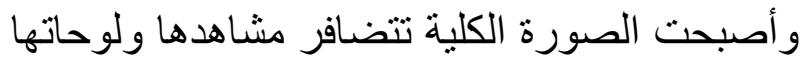
تضافراً بنائياً متماسكاً من أول القصيدة القيدة إلى آخر ها،

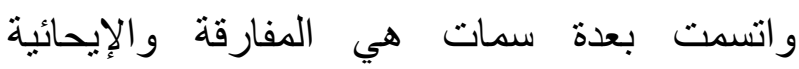
و الحركية والكلية والجمالية والتدويرية. فإذا كانت الصورة المقيدة قد وققت عند حد التضاد أو الترادف التفاد

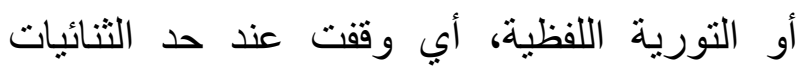
اللفظية فإن الصورة الحركية من منطلق تعدد معانيها

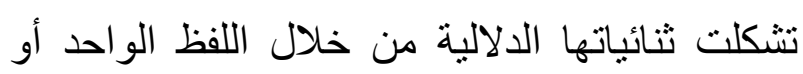

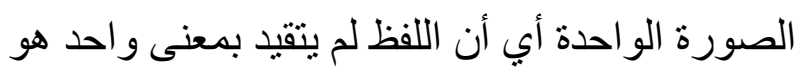

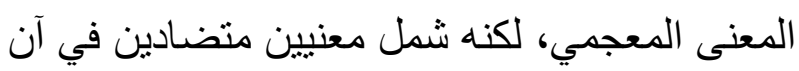
واحد "(ro).

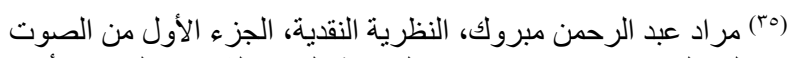
إلى النص، نحو نسق منهجي لدراسة النص الثنة الثعري النادي الأدبي 
منهجي لدراسة النص الشعري ) ط عـ، النادي الأدبي الثقافي، جدة.

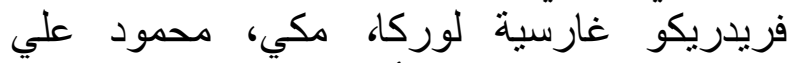

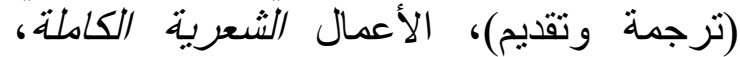
الدجلد الأول، المجلس الأعلى للإقافة، الطبعة الألية

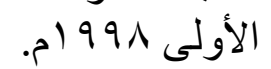

هال، جون وآخرون : مقالات ضد البنبيوية، ترجمة

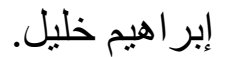

هلال، محمد غنيمي، الأب الدقارن، نهضة مصر، القاهرة، لو 99 أم.

وزان، عدنان محمد، مطالعات في الأدب المقارن،

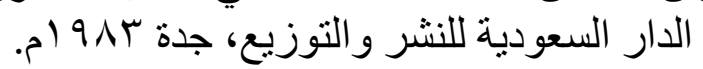

فيدريكو غارسيا لوركا، الموسوعة العزية العالية للشعر

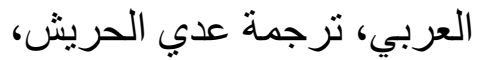

http://adab.com/world/modules.php?name=Sh

3er\&doWhat $=$ shqas \&qid $=81390 \& \mathrm{r}=\& \mathrm{rc}=9$ أمال الديب : موقع ثقافات /http://thaqafat.com/2015/05/26075

\section{تانياً: المصادر و المراجع الاجنبية}

Classic Poetry Series ، Federico Garcia Lorca Poems: The world's Poetry Archives، 2004.

Doubleday، N.F ، Studies in Poetry ، Harper ، New York ، 1949.

Wellek \& Warren ، Theory of Literature، Third edition، Harcourt Brace \& Company.USA. 1990.

Dudley ، L. ، The study of literature ،

Hougton \& Mifflim ، USA. 1928

Chilcott، Tem، Federico Garcia Lorca Poema Del Cante Jondo ، Poem of the deep Song (translated) :Parallel Text، 2007.
تيجم، بول فان: الأدب الدقارن، دار الفكر العربي،

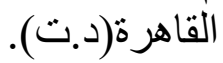

صدر هذا الكتاب دون تاريخ، ودون ذكر فئري

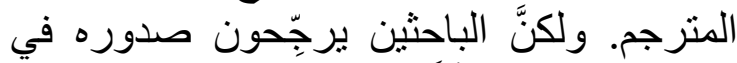

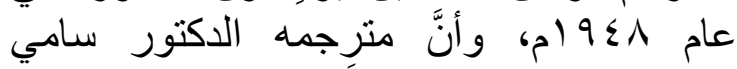

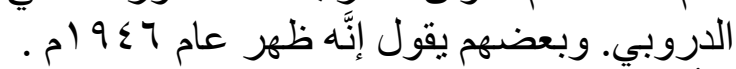

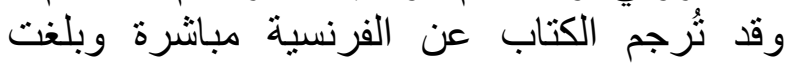

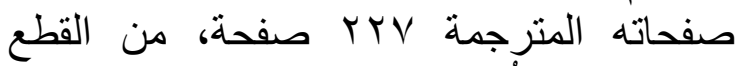

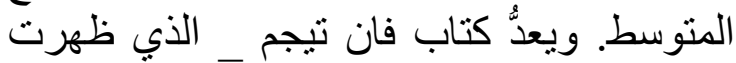

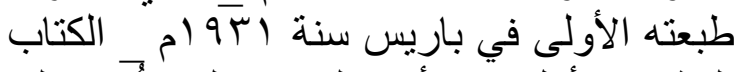

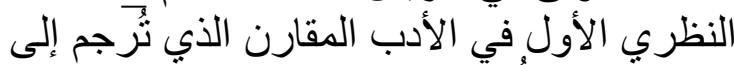

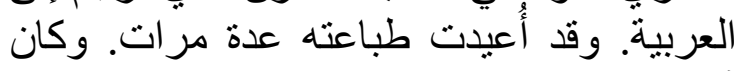

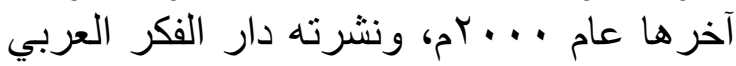

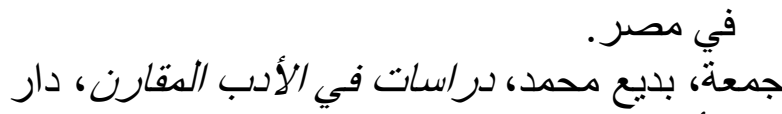

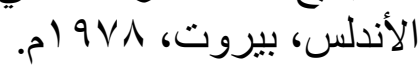

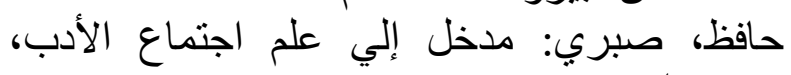

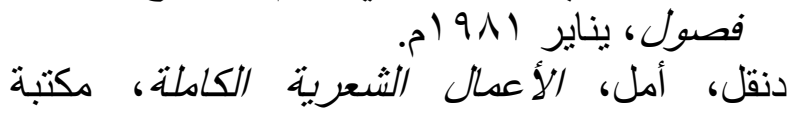

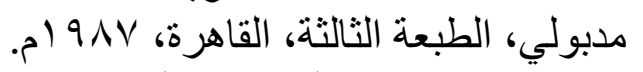
السرغيني، محمد: الثعر والتجربة: الوحانة الوحدة،

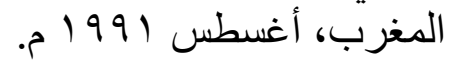
طحان، ريمون، الأدب الدقارن، دار الكتباب الكباب اللبناني

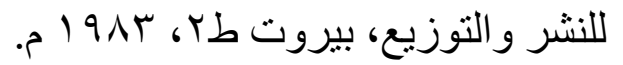

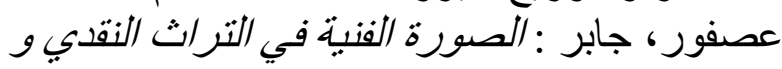

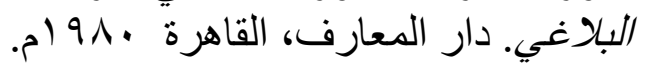

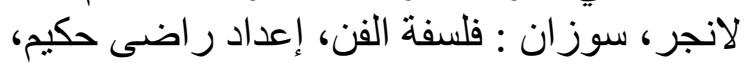

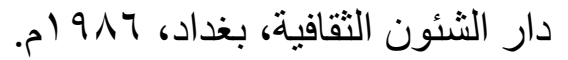

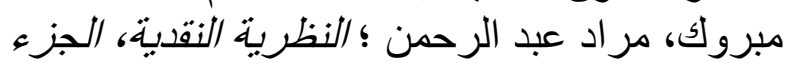
الأول (من الصوت إلى النص، نحو نسية نسقة النقة 


\title{
Representations of Death in the Poetry of Federico Garcia Lorca and Amal Dunqul: A Comparative Study
}

\author{
Mansour Mohsen Dhabab \\ King Abdulaziz University - Jeddah Saudi Arabia
}

\begin{abstract}
Death is an essential dimension of the poetry of both, Federico Garcia Lorca and Amal Dunqul, which highlights the many ways in which their respective lives were similar. Lorca was born on the $5^{\text {th }}$ of June 1898. He is considered by Spanish and international critics to be one of the most popular and most influential poets of the twentieth century. His celebrated poetry collection Poeta en Nueva York (translated in English as Poet in New York) was written during the period he attended the University of Columbia (19291930) and was published posthumously in 1940. In this collection، where death is a key theme, Lorca expresses his deep feelings of sadness and anguish. His refined empathy with fellow human beings is embodied in his identification with the struggles and aspirations of the poor throughout his life, which tragically ended with his assassination in 1936.

Like Lorca، Amal Dunqul remained faithful to the poetic and human values he prized right till the end of his life. In his poetry، he stands for the under trodden' a theme which is, for him, perennially linked to the dire situation of the Arab World and its many contradictions. Like Lorca, his poetry describes the reality he lived and upholds the values of truth ‘ justice and freedom.

This study tackles the theme of death and its philosophy in the poetry of each of them through a selection of poems in which it is the focal point. Highlighting the respective cultural backgrounds which shape the consciousness of each poet, the study analyses the concept and the factors which contribute to the prevalence of the theme of death in their poetry. It also explores the textual, imagery, and semiotic aspects associated with death in these poems, highlighting the unique style of each poet in relation to their use and expression. Keywords: Lorca, Amal Dungul, Comparative Study.
\end{abstract}

